\title{
SIMULATION OF A 3D UNSTEADY FLOW IN AN AXIAL TURBINE STAGE
}

\begin{abstract}
Petr STRAKA *
Abstract: The contribution deals with a numerical simulation of an unsteady flow in an axial turbine stage. The solution is performed using an in-house numerical code developed in the Aeronautical and Test Institute, PIc. in Prague. The numerical code is based on a finite volume discretization of governing equations (Favre averaged Navier-Stokes equations) and a two-equations turbulence model. The temporal integration is based on the implicit second-order backward Euler formula, which is realized through the iteration process in dual time. The proposed numerical method is used for solution of the 3D, unsteady, viscous turbulent flow of a perfect gas in the axial turbine stage. The flow path consists of an input nozzle, stator blade-wheel, rotor blade-wheel, a shroud-seal gap and a diffuser. Attention is paid to the influence of a secondary flow structures, such as generated vortices and flow in shroud-seal gap.
\end{abstract}

\section{INTRODUCTION}

The aim of this study is to investigate some properties of flow field in the axial turbine stage. At first the flow in the turbine stage was modeled in the middle section of the turbine stage as the two-dimensional turbulent unsteady flow. Furthermore, a calculation of the three-dimensional unsteady inviscid flow was performed. Boundary phenomena - secondary flow - have been studied using model of the threedimensional steady turbulent flow, using the "frozen rotor" technique. Effect of the secondary flow through the seal of the rotor was studied in a simplified model of a prismatic blade cascade using model of the three-dimensional steady turbulent flow.

The turbine stage consists of the stator and rotor wheels. The stator wheel contains 70 and the rotor wheel 90 blades. Therefor it was possible consider only periodic field of seven stator and nine rotor blades for the calculation. The hub diameter of the stage is $0.506 \mathrm{~m}$, the tip diameter is $0.597 \mathrm{~m}$ (blades span is $0.0455 \mathrm{~m}$ ), the axial chord of the stator is $0.01955 \mathrm{~m}$, the axial chord of the rotor is $0.025 \mathrm{~m}$ (both at the hub), the gap between stator and rotor is $0.005 \mathrm{~m}$. The shape of the blades is shown in Figure 1 . The angular speed of the rotor is $455.11 \mathrm{rad} \mathrm{s}^{-1}$. The inlet total pressure is $1.311 \cdot 10^{5} \mathrm{~Pa}$, the inlet total temperature is $55.81^{\circ} \mathrm{C}$, the angle of attac is $0^{\circ}$ and the outlet static pressure is $0.9538 \cdot 10^{5} \mathrm{~Pa}$. The in-house URANS numerical code was developed for calculation of flow in the turbine stage.

\section{2D MODEL}

In the introduction, solving of the problem was simplified to modeling of the two-dimensional unsteady turbulent flow in the unrolled circumferential cross-section of the stage at middle span of the blades. Equation (1) represents a system of governing equations that describe two-dimensional compressible turbulent flow of a perfect gas.

$$
\frac{\partial \mathbf{W}}{\partial t}+\frac{\partial \mathbf{F}_{i}}{\partial x_{i}}-\frac{\partial \mathbf{F}_{i}^{v}}{\partial x_{i}}=\mathbf{Q} .
$$

In equation (1) there is:

$$
\begin{aligned}
\mathbf{W} & =\left[\rho, \rho u_{j}, e, \rho k, \rho \omega\right]^{\mathrm{T}}, \\
\mathbf{F}_{i} & =\left[\rho u_{i}, \rho u_{i} u_{j}+\delta_{i j} p, u_{i}(e+p), \rho u_{i} k, \rho u_{i} \omega\right]^{\mathrm{T}}, \\
\mathbf{F}_{i}^{v} & =\left[0, \tau_{i j}, u_{j} \tau_{i j}-q_{i},\left(\mu+\sigma_{k} \mu_{t}\right) \frac{\partial k}{\partial x_{i}},\left(\mu+\sigma_{\omega} \mu_{t}\right) \frac{\partial \omega}{\partial x_{i}}\right]^{\mathrm{T}}, \\
\mathbf{Q} & =\left[0,0,0,0, P_{k}-D_{k}, P_{\omega}-D_{\omega}-C_{D}\right]^{\mathrm{T}},
\end{aligned}
$$

\footnotetext{
* Ing. Petr Straka, PhD., Aeronautical Research and Test Institute, Plc, Beranovýh 130, 19905 Praha-Letňany, straka@vzlu.cz
} 


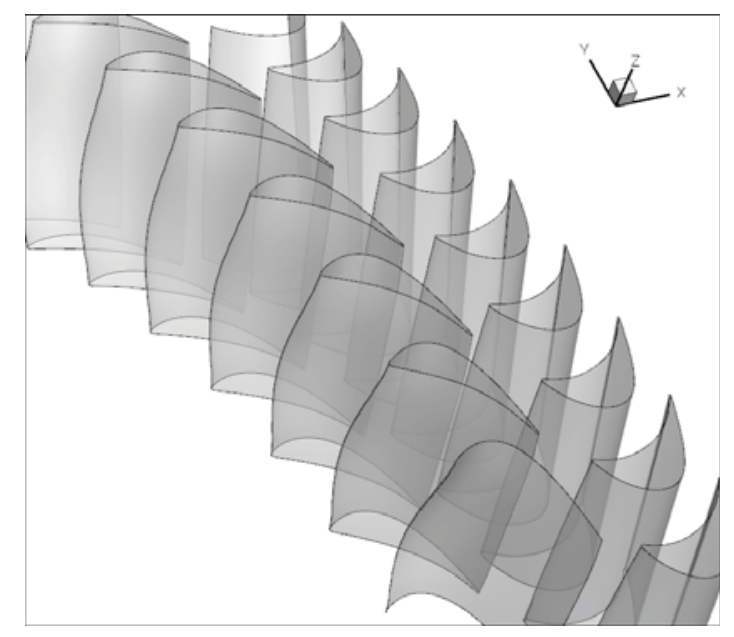

Figure 1: Stator and rotor blades

where:

$$
\begin{aligned}
P_{k} & =\min \left\{P, \rho k \sqrt{S_{i j} S_{i j}}\right\} \\
P & =\left\{\mu_{t}\left[\left(\frac{\partial u_{i}}{\partial x_{j}}+\frac{\partial u_{j}}{\partial x_{i}}\right)-\frac{2}{3} \frac{\partial u_{k}}{\partial x_{k}} \delta_{i j}\right]-\frac{2}{3} \rho k \delta_{i j}\right\} \frac{\partial u_{i}}{\partial x_{k}} \\
D_{k} & =\beta_{k} \rho k \omega \\
P_{\omega} & =\alpha \frac{\omega}{k} P_{k} \\
D_{\omega} & =\beta_{\omega} \rho \omega^{2} \\
C_{D} & =\frac{1}{2} \frac{\rho}{\omega} \max \left(\frac{\partial k}{\partial x_{j}} \frac{\partial \omega}{\partial x_{j}}, 0\right) .
\end{aligned}
$$

The system of governing equations is complemented by constitutive relations:

$$
\begin{aligned}
p & =(\kappa-1)\left(e-\rho \frac{u_{j}^{2}}{2}\right), \\
q_{i} & =-\left(\frac{\mu}{P r}+\frac{\mu_{t}}{P r_{t}}\right) \frac{\kappa r}{\kappa-1} \frac{\partial T}{\partial x_{i}}, \\
\tau_{i j} & =\left(\mu+\mu_{t}\right)\left[\left(\frac{\partial u_{i}}{\partial x_{j}}+\frac{\partial u_{j}}{\partial x_{i}}\right)-\frac{2}{3} \frac{\partial u_{k}}{\partial x_{k}} \delta_{i j}\right]-\frac{2}{3} \rho k \delta_{i j}, \\
\mu & =\mu_{0}\left(\frac{T}{T_{0}}\right)^{\frac{3}{2}} \frac{T_{0}+S}{T+S}, \\
\mu_{t} & =\frac{\rho k}{\omega} .
\end{aligned}
$$

The system of governing equations is discretized using the cell-centered finite volume method on a multiblock structured quadrilateral mesh. The temporal discretization is performed using second-orded backward Euler formula in implicit form, which is realized through a dual iterative process:

$$
\left(\frac{3}{2} \mathbf{I}+\Delta t \frac{\partial \mathbf{R}_{i}^{n, \nu}}{\partial \mathbf{W}_{i}^{n, \nu}}\right) \Delta \mathbf{W}_{i}^{n, \nu+1 / 2}+\Delta t \sum_{j=1}^{4} \frac{\partial \mathbf{R}_{i}^{n, \nu}}{\partial \mathbf{W}_{j}^{n, \nu}} \Delta \mathbf{W}_{j}^{n, \nu+1 / 2}=-\frac{3 \mathbf{W}_{i}^{n, \nu}-4 \mathbf{W}_{i}^{n}+\mathbf{W}_{i}^{n-1}}{2}-\Delta t \mathbf{R}_{i}^{n, \nu}
$$


where $\mathbf{W}^{n, 0}:=\mathbf{W}^{n}, \Delta \mathbf{W}^{n, \nu+1 / 2}=\Delta \mathbf{W}^{n, \nu+1}-\Delta \mathbf{W}^{n, \nu}$ and $\mathbf{W}^{n+1}:=\mathbf{W}^{n, \nu^{*}}$, where $\mathbf{W}^{n, \nu^{*}}$ is a steady solution in the dual iterative process. In equation (17) there is:

$$
\mathbf{R}_{i}=\frac{1}{V_{i}} \sum_{j=1}^{4}\left[\Phi^{i n v}\left(\mathbf{W}_{j}^{L}, \mathbf{W}_{j}^{R}, \mathbf{n}_{j}\right)-\Phi^{v i s}\left(\mathbf{W}_{j}^{C},(\nabla \mathbf{W})_{D_{j}^{\text {dual }}}, \mathbf{n}_{j}\right)\right] s_{j} .
$$

The inviscid numerical fluxes $\Phi^{i n v}$ are calculated using the exact solution of the 1D Rieman problem in normal direction to the cell edges. The viscous numerical fluxes $\Phi^{v i s}$ are calculated using the central scheme and the gradient of the state vector $\nabla \mathbf{W}$ is calculated using the Green-Gauss theorem on a dual cells. Higher order of accuracy in space is obtained using linear reconstruction with the Van Albada limiter.
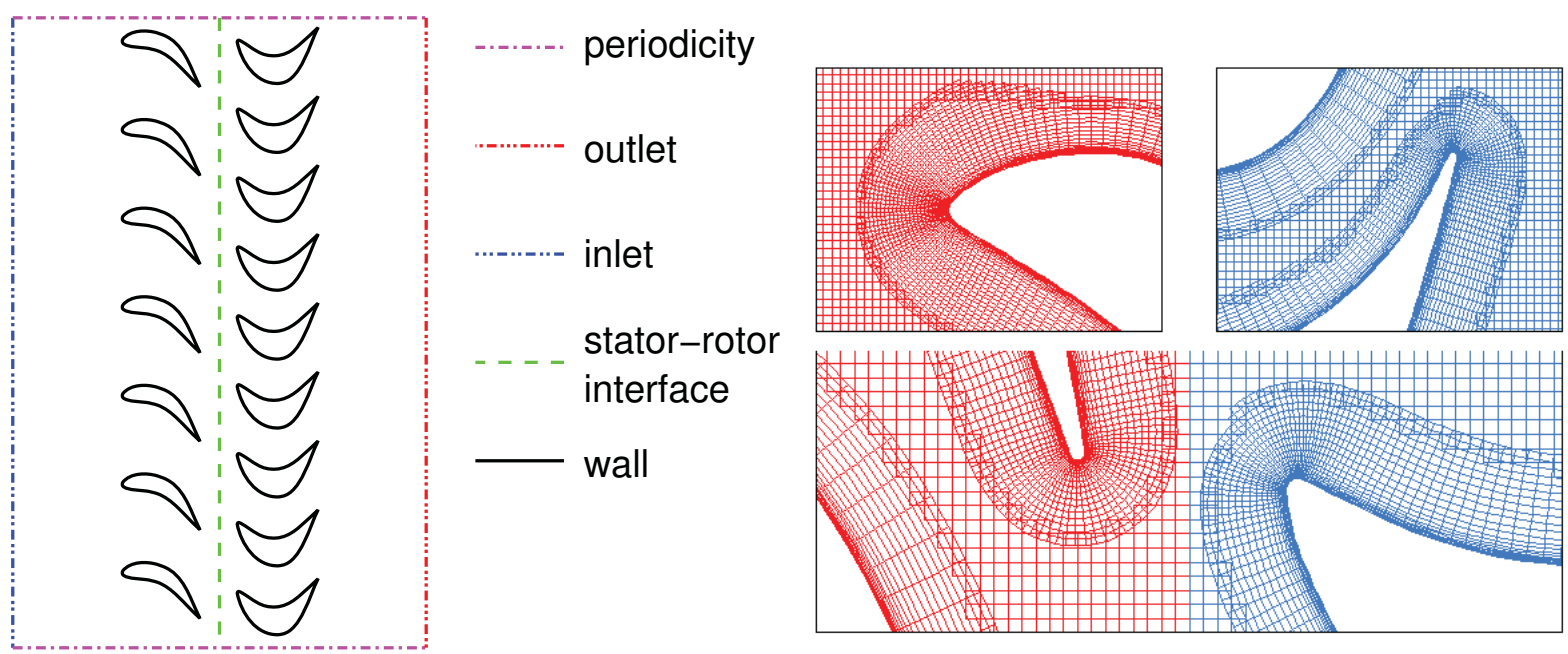

Figure 2: Scheme of the computational domain and details of mesh

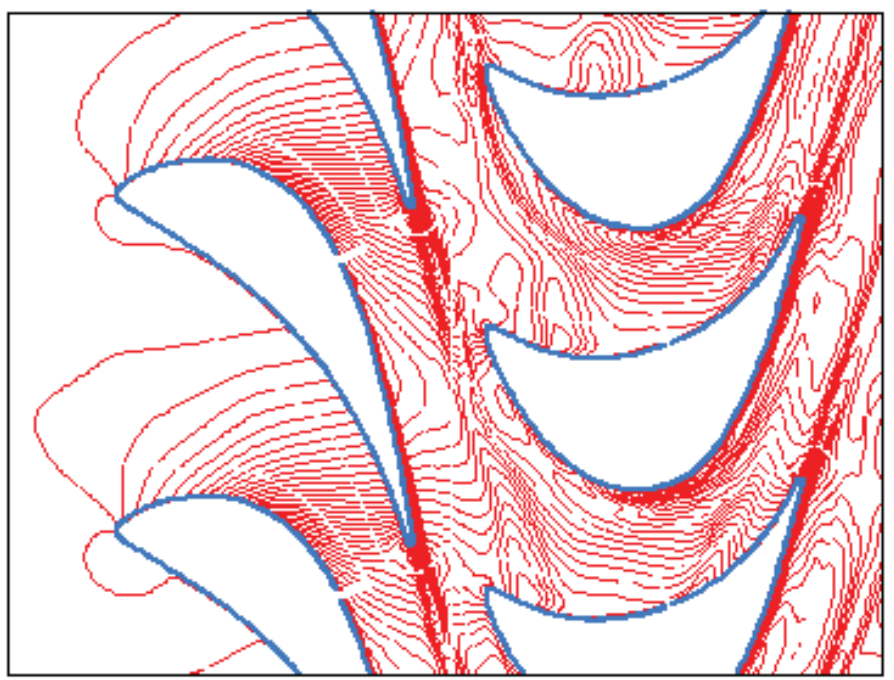

Figure 3: Mach number isolines

At the interface between stator and rotor part of computational domain, the continuity of density and pressure is prescribed (with respect to the temporal dependent mutual shift of the rotor blades to the 

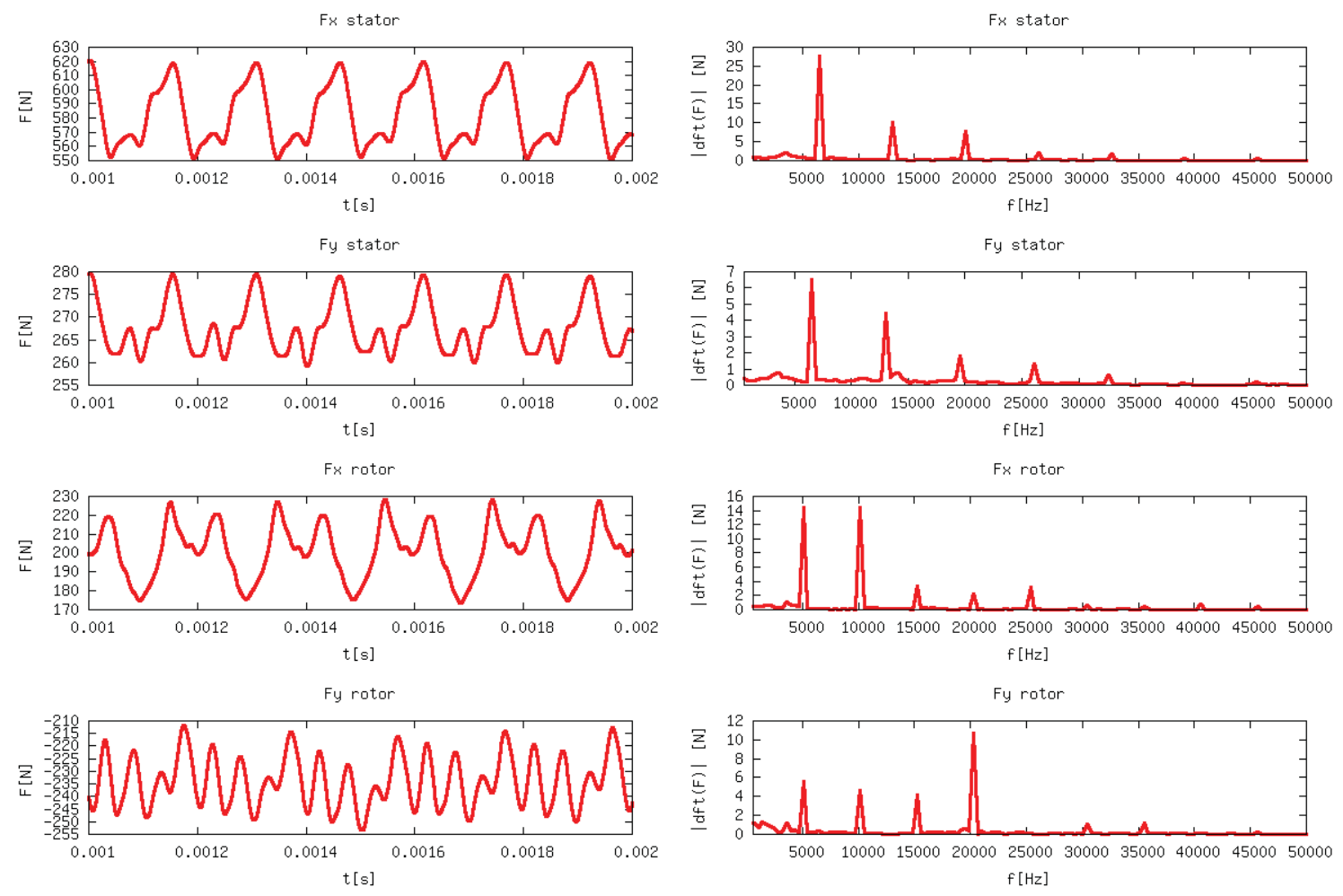

Figure 4: Time behaviour and frequency spectrum of the forces on stator and rotor blades

stator blades). The velocity vector at the interface respects the circumferential speed $v_{c r}=125.61 \mathrm{~m} \mathrm{~s}^{-1}$. Scheme of the computational domai and details of the mesh are shown in Figure 2. The flow-field in Mach number isolines form is shown in Figure 3. Time behaviour and frequency spectrum of the forces on stator and rotor blades are shown in Figure 4.

\section{3D MODEL}

Modeling of the stator-rotor interaction in a 3D configuration was first performed using the model of the unsteady inviscid flow. Subsequently, the calculation was performed with the model of the turbulent flow using the "frozen rotor" technique.

\subsection{INVISCID MODEL}

The model of the three-dimensional compressible inviscid flow of the perfect gas is described by the system of governing equations:

$$
\frac{\partial \mathbf{W}}{\partial t}+\frac{\partial \mathbf{F}_{i}}{\partial x_{i}}=\mathbf{0},
$$

where

$$
\begin{aligned}
& \mathbf{W}=\left[\rho, \rho u_{j}, e\right]^{\mathrm{T}}, \\
& \mathbf{F}_{i}=\left[\rho u_{i}, \rho u_{i} u_{j}+\delta_{i j} p, u_{i}(e+p)\right]^{\mathrm{T}},
\end{aligned}
$$

The system of governing equations (19) is complemented by constitutive relation (12). Because the rotor part of the computational domain moves, we must use the integral form of system (19) taking into account the motion of the control volume:

$$
\frac{\partial}{\partial t} \int_{V} \mathbf{W} d V+\oint_{S}\left(\mathbf{F}_{i} n_{i}-\mathbf{W} \mathbf{v}_{b} \mathbf{n}\right) d S
$$


where $\mathbf{n}=\left(n_{1}, n_{2}, n_{3}\right)$ is the unit outward normal vector to the surface of the control volume, $\mathbf{v}_{b}=$ $\left(v_{b 1}, v_{b 2}, v_{b 3}\right)$ is the velocity vector of the motion of the control volume surface. In the stator part of the computational domain is simply $\mathbf{v}_{b}=(0,0,0)$. In the rotor part of the computational domain, which rotates around the $x$-axis with angular velocity $\omega$ is $\mathbf{v}_{b}=(0,-z \omega, y \omega)$. The system of governing equations (19) is discretized using the cell-centered finite volume method on a multiblock structured hexahedral mesh:

$$
\frac{\partial\left(V_{i} \mathbf{W}_{i}\right)}{\partial t}=-\Delta t \sum_{j=1}^{6}\left[\Phi^{i n v}\left(\mathbf{W}_{j}^{L}, \mathbf{W}_{j}^{R}, \mathbf{n}_{j}\right)-\mathbf{W}_{i}^{C} \mathbf{v}_{b j} \mathbf{n}_{j}\right] d s_{j} .
$$

Because the cells doesn't change shape and volume, it holds:

$$
\begin{aligned}
\frac{\partial V}{\partial t} & =0 \\
\sum_{j=1}^{6} \mathbf{v}_{b j} \mathbf{n}_{j} d s_{j} & =0 .
\end{aligned}
$$

The temporal discretization is performed using second-orded backward Euler formula in implicit form, which is realized through a dual iterative process:

$$
\left(\frac{3}{2} \mathbf{I}+\Delta t \frac{\partial \mathbf{R}_{i}^{n, \nu}}{\partial \mathbf{W}_{i}^{n, \nu}}\right) \Delta \mathbf{W}_{i}^{n, \nu+1 / 2}+\Delta t \sum_{j=1}^{6} \frac{\partial \mathbf{R}_{i}^{n, \nu}}{\partial \mathbf{W}_{j}^{n, \nu}} \Delta \mathbf{W}_{j}^{n, \nu+1 / 2}=-\frac{3 \mathbf{W}_{i}^{n, \nu}-4 \mathbf{W}_{i}^{n}+\mathbf{W}_{i}^{n-1}}{2}-\Delta t \mathbf{R}_{i}^{n, \nu}
$$

where $\mathbf{W}^{n, 0}:=\mathbf{W}^{n}, \Delta \mathbf{W}^{n, \nu+1 / 2}=\Delta \mathbf{W}^{n, \nu+1}-\Delta \mathbf{W}^{n, \nu}$ and $\mathbf{W}^{n+1}:=\mathbf{W}^{n, \nu^{*}}$, where $\mathbf{W}^{n, \nu^{*}}$ is a steady solution in the dual iterative process. In equation (26) there is:

$$
\mathbf{R}_{i}=\frac{1}{V_{i}} \sum_{j=1}^{6}\left[\Phi^{i n v}\left(\mathbf{W}_{j}^{L}, \mathbf{W}_{j}^{R}, \mathbf{n}_{j}\right)-\mathbf{W}_{i}^{C} \mathbf{v}_{b j} \mathbf{n}_{j}\right] d s_{j} .
$$

The inviscid numerical fluxes $\Phi^{i n v}$ are calculated using the exact solution of the 1D Rieman problem in normal direction to the cell edges. Higher order of accuracy in space is obtained using linear reconstruction with the Van Albada limiter.

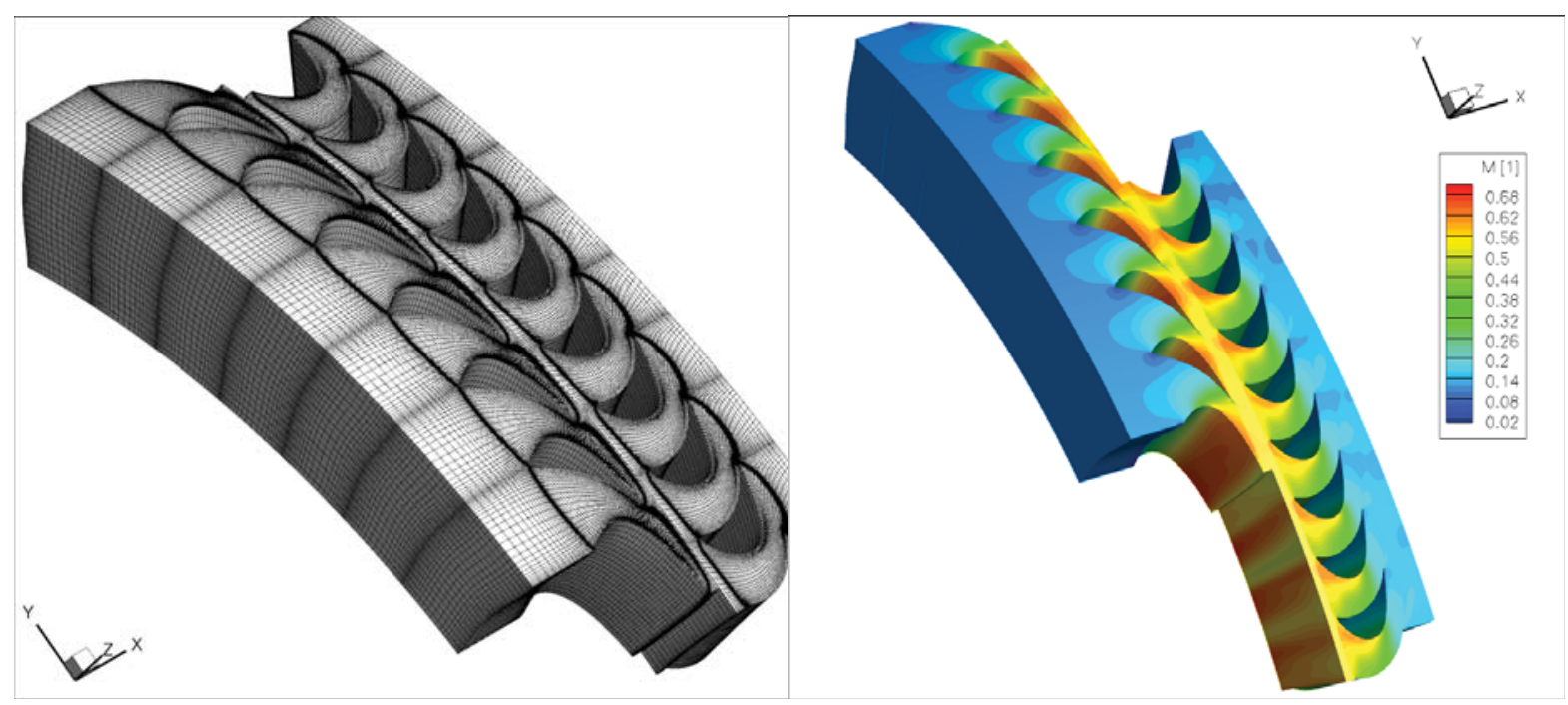

Figure 5: Multiblock structured hexahedral mesh and Mach number field

The multiblock structured hexahedral mesh and the Mach number field ar shown in Figure 5. Distribution of the mean value and the amplitude of the first harmonic frequence of the normalized mass flux in the output cross-section is shown in Figure 6. Distribution of the mean value and the amplitude of the first harmonic frequence of the temperature in the output cross-section is shown in Figure 7. 


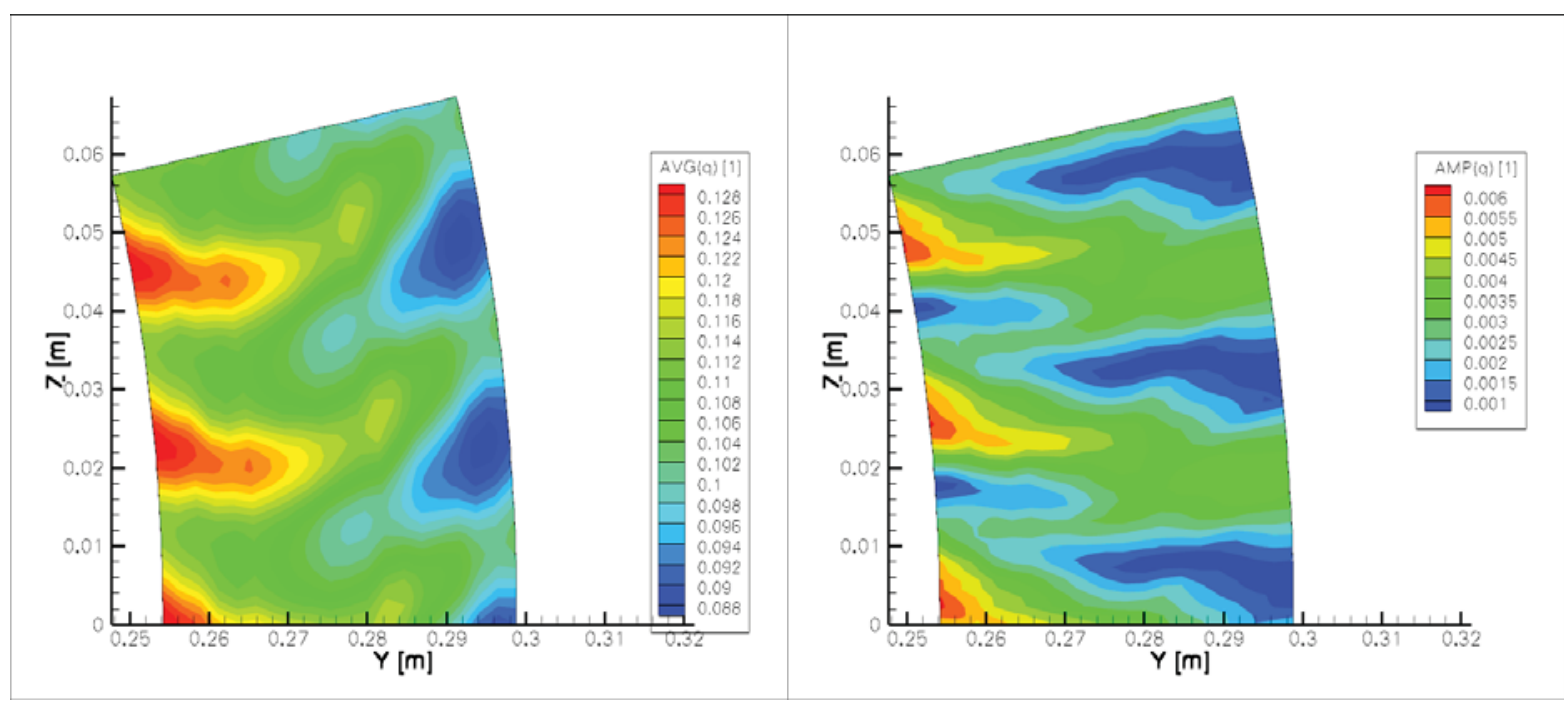

Figure 6: The mean value (left) and the amplitude of the first harmonic frequence (right) of the normalized mass flux

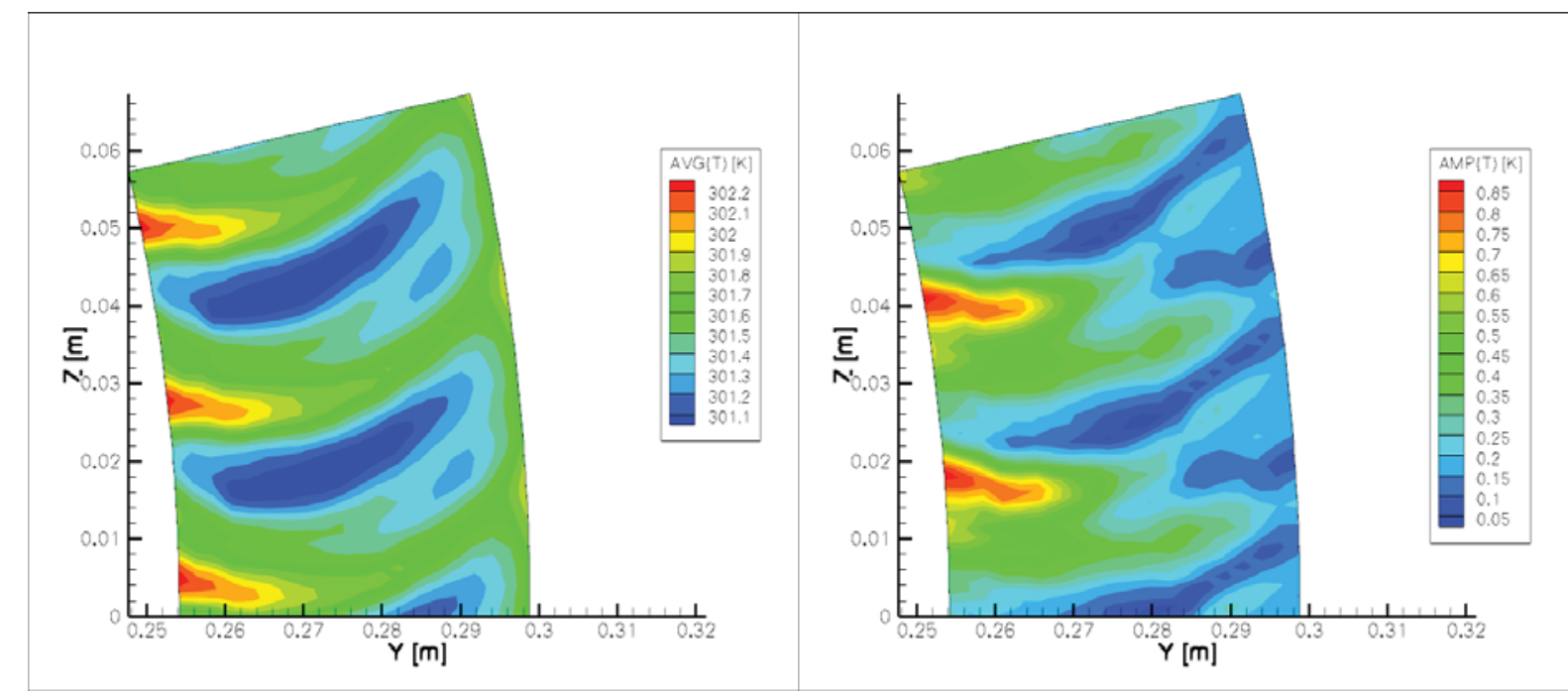

Figure 7: The mean value (left) and the amplitude of the first harmonic frequence (right) of the temperature

\subsection{TURBULENT MODEL}

The effect of the secondary flow structures is modeled using a simplified model of three-dimensional turbulent flow using the "frozen rotor" technique. When using this technique, the rotor is not moving towards the stator, only takes into account the circumferential speed at the interface between the stator and rotor parts of the computational domain. It means that it is a model of steady flow. The model of the three-dimensional compressible turbulent flow of the perfect gas is described by equations (1) to (16). With respect to the stationarity of the flow, we can use first order backward Euler formula for the temporal discretization:

$$
\left(\mathbf{I}+\Delta t \frac{\partial \mathbf{R}_{i}^{n}}{\partial \mathbf{W}_{i}}\right) \Delta \mathbf{W}_{i}^{n+1 / 2}+\Delta t \sum_{j=1}^{6} \frac{\partial \mathbf{R}_{i}^{n}}{\partial \mathbf{W}_{j}} \Delta \mathbf{W}_{j}^{n+1 / 2}=-\Delta t \mathbf{R}_{i}^{n},
$$


where $\Delta \mathbf{W}^{n+1 / 2}=\mathbf{W}^{n+1}-\mathbf{W}^{n}$ and

$$
\mathbf{R}_{i}=\frac{1}{V_{i}} \sum_{j=1}^{6}\left[\Phi^{i n v}\left(\mathbf{W}_{j}^{L}, \mathbf{W}_{j}^{R}, \mathbf{n}_{j}\right)-\Phi^{v i s}\left(\mathbf{W}_{j}^{C},(\nabla \mathbf{W})_{D_{j}^{d u a l}}, \mathbf{n}_{j}\right)\right] s_{j}
$$

The inviscid numerical fluxes $\Phi^{i n v}$ are calculated using the exact solution of the 1D Rieman problem in normal direction to the cell edges. The viscous numerical fluxes $\Phi^{v i s}$ are calculated using the central scheme and the gradient of the state vector $\nabla \mathbf{W}$ is calculated using the Green-Gauss theorem on a dual cells. Higher order of accuracy in space is obtained using linear reconstruction with the Van Albada limiter.

Figure 8 shows field of the static temperature and Figure 9, on which the stream-lines are displayed, shows considerable swirl flow in the rotor part, especially at the hub of blade. Vortices affect more than one third of the flow field at the outlet.



Figure 8: Temperature field

\section{EFFECT OF THE SHROUD-SEAL}

The rotor wheel is fitted shroud with a seal. Gaps in the seals are relatively large due to the length of the blade. Secondary flow in the seal influences the main stream behind the rotor. Effect of secondary flow through the seal is studied on a simplified model of the prismatic straight rotor blades as shown in the figure 10 (left). The upper wall of the seal moves at speed $136 \mathrm{~m} / \mathrm{s}$ in the direction $z$.

Field of the Mach number in the longitudinal section of the blade cascade with the seal is shown in the Figure 10 (right). Stream traces through the seal are shown in the Figure 11. The mass flow through the prismatic blade cascade is $0.0774 \mathrm{~kg} / \mathrm{s}, 3.35 \%$ from this one flows through the seal. 




Figure 9: Secondary flow structures

\section{Conclusion}

In this work, the in-house numerical code for solving compressible, turbulent and inviscid, steady and unsteady, two-dimensional and three-dimensional flow in the stator-rotor system was developed. Temporal behaviour of the forces acting on the blades and their frequency spectrum was calculated. Furthermore, the unsteady phenomena were evaluated at the output of the rotor wheels - mean values and amplitude of first harmonic frequency of flow field values. Study of the secondary flow (vortex structures, flow in the seal) showed a large swirl flow field at the output of the rotor wheel.

\section{ACKNOWLEDGEMENT}

This work was supported by the Ministry of Industry and Trade of the Czech Republic through the project FR-TI3/432. 


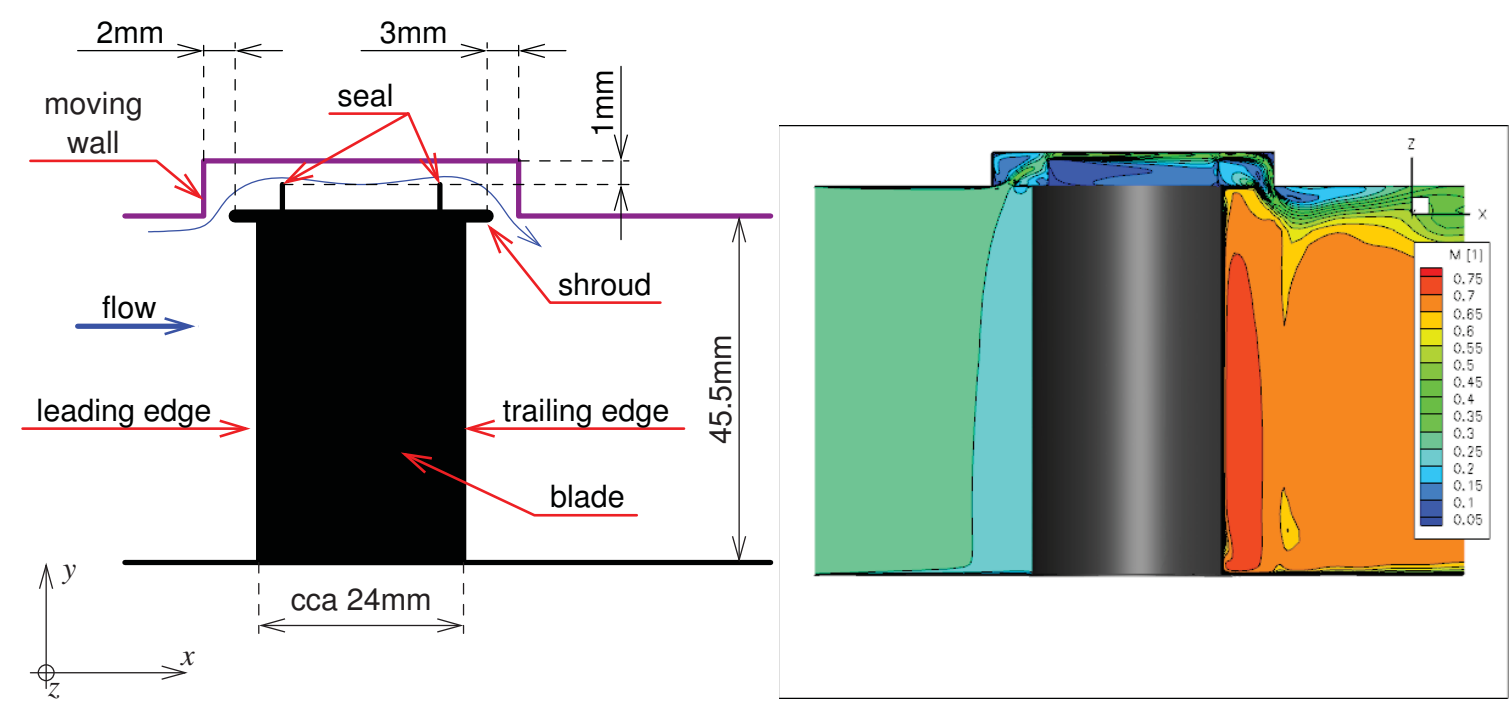

Figure 10: Scheme of the shroud seal and Mach number field

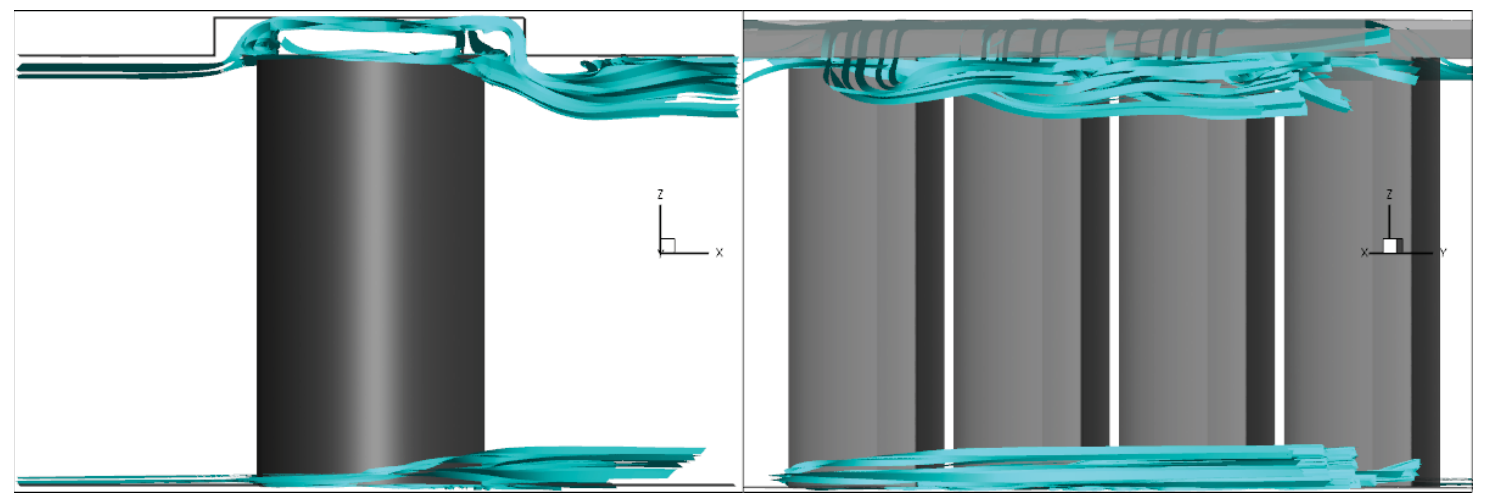

Figure 11: Seal - secondary flow structures

\section{REFERENCES}

[1] Kok J. C., Resolving the Dependence on Freestream Values for Turbulence Model, AIAA Journal, 38, No. 7 (2000)

[2] Feistauer M., Felcman J. and Straškraba I., Mathematical and Computational Methods for Compressible Flow, Oxford University Press (2003)

[3] Straka P., Unsteady solution of a stator-rotor interaction, Fifth European Conference on Computational Fluid Dynamics, Lisbon 2010

[4] Straka P., Halama J., Fürst J., Rudas B., Porovnání výsledků numerických výpočtů nestacionárního proudění v turbínovém stupni ST-6, Research report VZLÚ R-4562, Prague 2009, (in Czech)

[5] Straka P., Výpočet 3D nestacionárního nevazkého proudění v turbínovém stupni ST6 Research report VZLÚ R-4910, Prague 2010, (in Czech) 